\title{
Evaluation of Two Decades of Cryphonectria parasitica Hypovirus Introduction in an American Chestnut Stand in Wisconsin
}

\author{
Mark L. Double, Andrew M. Jarosz, Dennis W. Fulbright, Anita Davelos Baines, and William L. MacDonald ${ }^{\dagger}$
}

First and fifth authors: Division of Plant and Soil Sciences, West Virginia University, Morgantown 26506; second author: Departments of Plant Biology, and Plant, Soils and Microbial Sciences, and The Program in Ecology, Evolutionary Biology and Behavior, Michigan State University, East Lansing 48824; third author: Department of Plant, Soil and Microbial Sciences, Michigan State University, East Lansing 48824; and fourth author: Department of Biology, University of Wisconsin-La Crosse, La Crosse 54601.

Accepted for publication 5 January 2018.

\begin{abstract}
Hypovirus-infected Cryphonectria parasitica strains were introduced in a large stand of American chestnut ( $>4,000$ individuals) in western Wisconsin (USA) to evaluate whether hypoviruses can serve as biological control agents. They were deployed by treating cankers from 1992 to 1997 and again from 2004 to 2014. After 17 years of hypovirus introductions within an area of the stand with the longest history of disease, isolation of hypovirus-infected strains increased from 55\% in 1994 to $86 \%$ in 2014 from cankers that were

cankers on nearby trees that received no treatment. Tree survivorship over the 23-year study period for trees with treated cankers was $51 \%$ compared with $31 \%$ for trees that were not treated. Introduction of hypovirus has resulted in the regrowth of the crowns of many large-diameter trees. Putative recovery of American chestnut in this stand provides evidence that prolonged hypovirus treatment can act as a biological control when limited numbers of vegetative compatibility types of $C$. parasitica exist.
\end{abstract} treated. During the same period, isolation from cankers that arose on trees with treated cankers increased from 29 to $72 \%$ and from 15 to $84 \%$ for

Mycoviruses, viruses that infect fungi, are found in all major fungal phyla (Chytridiomycota, Zygomycota, Ascomycota, and Basidiomycota), and there is increasing evidence of their potential to be effective biological control agents for a wide range of plant diseases (Pearson et al. 2009; Xie and Jiang 2014). The presence of mycoviruses has been shown to reduce the virulence (hypovirulence) of several plant pathogens, including Botrytis cinerea (Castro et al. 2003), Fusarium circinatum (Muñoz-Adalia et al. 2016), Sclerotinia sclerotiorum (Yu et al. 2010), and Ophiostoma novo-ulmi (Doherty et al. 2006; Muñoz-Adalia et al. 2016).

The phenomenon of hypovirulence, in which mycoviruses variably attenuate virulence of the chestnut blight fungus, Cryphonectria parasitica (Murr.) Barr, was described on European chestnut (Castanea sativa [Mill.]) by French mycologist Jean Grente (Grente 1981; Grente and Berthelay-Sauret 1978). Field trials by Grente and Berthelay-Sauret (1978) using hypovirulent strains were so successful in controlling chestnut blight on European chestnut that the French Ministry of Agriculture set up a biological control program to assist chestnut growers with blight control (Heiniger and Rigling 1994). Success in many European field trials stimulated interest in North America where chestnut blight devastated 200 million acres of American chestnut (Castanea dentata [Marsh.] Borkh.) during the first half of the 20th century (Kuhlman 1978; Van Alfen et al. 1975), relegating the species to understory sprouts from extant root systems (Clark et al. 2016). Field applications of hypoviruscontaining $C$. parasitica isolates in North America have met with limited success, possibly due to: the high diversity in vegetative compatibility (VC) types in $C$. parasitica, restricting the spread of

†Corresponding author: W. L. MacDonald; E-mail: macd@wvu.edu

Funding: This study was financially supported, in part, by The American Chestnut Foundation. The work of D. W. Fulbright and A. M. Jarosz was funded in part by MSU AgBioResearch. Scientific Article 3333 of the West Virginia Agricultural and Forestry Experiment Station, Morgantown.

(c) 2018 The American Phytopathological Society
Additional keywords: chestnut blight, epidemiology, mycovirus.

hypovirus (Anagnostakis et al. 1986; Cortesi and Milgroom 1998, 1999); the higher level of susceptibility of American chestnuts when compared with their European relatives (Viéitez and Merkle 2005); and the inability of infected chestnuts to compete successfully with other tree species in eastern forests (Griffin 2000; MacDonald and Fulbright 1991). Here we report on the long-term application of hypoviruses in an infected stand of American chestnut near West Salem, Wisconsin.

The stand represents an example of relocation of a tree species outside its natural range. This introduction occurred in the $1880 \mathrm{~s}$ when 8 to 10 American chestnuts from the native range were planted at a site near West Salem, WI (Cummings Carlson et al. 1998; McGrath 1992). These trees served as the founders for a population of chestnuts that became the dominant species on a portion of this 36-ha mixed hardwood stand they occupy (Paillet and Rutter 1989). The stand was comprised of more than 4,000 healthy chestnut trees until 1987 when cankers were detected on four trees. From 1987 through 1991 attempts were made to eradicate the disease by felling and burying infected stems. Despite these efforts, the number of infected trees rose steadily, prompting the landowners to support the introduction of hypoviruses in 1992.

Several characteristics of the stand were thought to increase the probability that hypovirus introductions would be successful. First, a single VC type (WS-1) (Table 1) was identified from strains isolated from cankers at the site (McGuire et al. 2005) in 1990 to 1991. Since the $C$. parasitica population was essentially clonal, the West Salem chestnut stand offered a unique opportunity to initiate biological control using hypoviruses because the barriers to hypovirus spread among strains imposed by VC were lacking. Second, the site shared several characteristics (e.g., isolated population and vigorous chestnut growth) with sites in Michigan where American chestnuts are naturally undergoing hypovirus-associated recovery (Davelos and Jarosz 2004; Fulbright et al. 1983). The decision to use the site as a natural laboratory for the deployment of hypovirus seemed ideal. This paper details the results of deploying hypoviruses in a portion of the stand (hereafter referred to as the Disease Center), an area where the first infections were discovered. 
The study objective was to evaluate whether canker applications of hypovirus-infected $C$. parasitica strains would result in a level of hypovirus acquisition and establishment needed to promote the growth and survivorship (biological control of the disease) of the trees.

\section{MATERIALS AND METHODS}

C. parasitica hypovirulent strains. Several hypoviruses were available as potential biological control agents, each imparting different effects on C. parasitica (Nuss and Hillman 2011). The decision was made to use a hypovirus, Cryphonectria hypovirus 3 (CHV-3) from Manistee County, Michigan (designated COLI) (Fulbright et al. 1983; Peever et al. 1997) because it had been associated with recovery of American chestnut populations in Michigan, and there were fewer restrictions associated with obtaining state and federal approval for the release of a North American hypovirus. Because CHV-3/COLI did not spread well within the West Salem stand after 3 years of introduction (1992 to 1994), a second hypovirus, Cryphonectria hypovirus 1 (CHV-1/EURO7) (Chen and Nuss 1999), was deployed in 1995 to 1997 and 2004 to 2014. The fungal strains and hypoviruses used in this study are described in Table 1.

Hypovirus transmission into West Salem strain backgrounds. The hypovirus CHV-3/COLI was successfully transmitted to VC type WS-1 when the two strains were coinoculated side-by-side on excised stems of $C$. dentata. Presumptive WS-1 (COLI)-infected strains were isolated from the WS-1 side of the pairings and subcultured on potato dextrose agar (PDA, Becton, Dickinson and Co., Franklin Lakes, NJ). When slow growing, orange colonies were chosen as putatively infected, transmission of the CHV-3/COLI hypovirus was confirmed in the WS- 1 background after hypovirus transmission was morphologically observed when cocultured on PDA. The second hypovirus, CHV-1/EURO7, was transmitted readily via coinoculation on PDA into WS-1 and two additional common VC types, WS-2 and WS-3, after their detection in the stand in 1996 and 1997, respectively. Isolates 25-1, 108-1, and 133-1 were used as representatives of VC types WS-1, WS-2, and WS-3, respectively. Infection of virulent $C$. parasitica isolates by the CHV-3/COLI and CHV-1/EURO7 hypoviruses resulted in unique morphologies on PDA (Fig. 1). Slow growing orange strains with minimal aerial hyphae were categorized as CHV-3/COLI-infected; fast growing white strains as CHV-1/EURO7-infected; fast growing orange strains as virulent, hypovirus-free. The two hypoviruses also had differing banding patterns upon dsRNA extraction and gel electrophoresis (Morris and Dodds 1979, Method 1). Morphology and dsRNA patterns together were used to distinguish hypovirus-infected isolates in the laboratory from each other and wild-type isolates collected from field samples.

Canker sampling, hypovirus assessment, and VC type determination. In order to assess VC type and hypovirus acquisition in the $C$. parasitica cankers, 12 2-mm-diameter bark plugs were removed annually from cankers with a bone marrow instrument (Lee-Lok, 11-guage, 4-inch, Lee Medical, Skillman, NJ) and processed according to McGuire et al. (2005). Cultures from these samples were used to ascertain the hypovirus infection status of the C. parasitica strains using the morphological criteria described previously. Cultures that were not $C$. parasitica were recorded as non-C.p. These data were compiled for a longitudinal characterization of hypovirus acquisition by each sampled canker.

VC was assayed on a bromocresol green agar medium (PDAg) described by Powell (1995), modified by adding $0.5 \mathrm{ml}$ of Tween20, decreasing tannic acid to $500 \mathrm{mg} / \mathrm{liter}$ and increasing the extra agar to $12 \mathrm{~g} /$ liter. Isolates were paired on PDAg in total darkness for 7 to 10 days at $22^{\circ} \mathrm{C}$ and scored on the presence/absence of a barrage (Anagnostakis 1977). Prior to 1997, one representative virulent isolate from each canker was paired on PDAg with isolate 25-1, representing VC group WS-1. When additional VC types were discovered in 1996 (WS-2) and 1997 (WS-3), a virulent isolate from each canker was tested against WS-1, WS-2, and WS-3. All isolates identified as incompatible with these three VC groups were retested. Additional VC types (WS-4 through WS-15) were discovered from 2000 to 2010. Isolates incompatible with WS-1, WS-2, and WS-3 a second time were then paired with tester isolates representing WS-4 through WS-15 (McGuire et al. 2005).

Hypovirus treatment. Trees were assessed annually (late May/ early June) from 1992 to 2014. Each tree was assigned a unique number when first infected and cankers were numbered sequentially on individual trees as they developed. Between 1992 to 1994, an agar

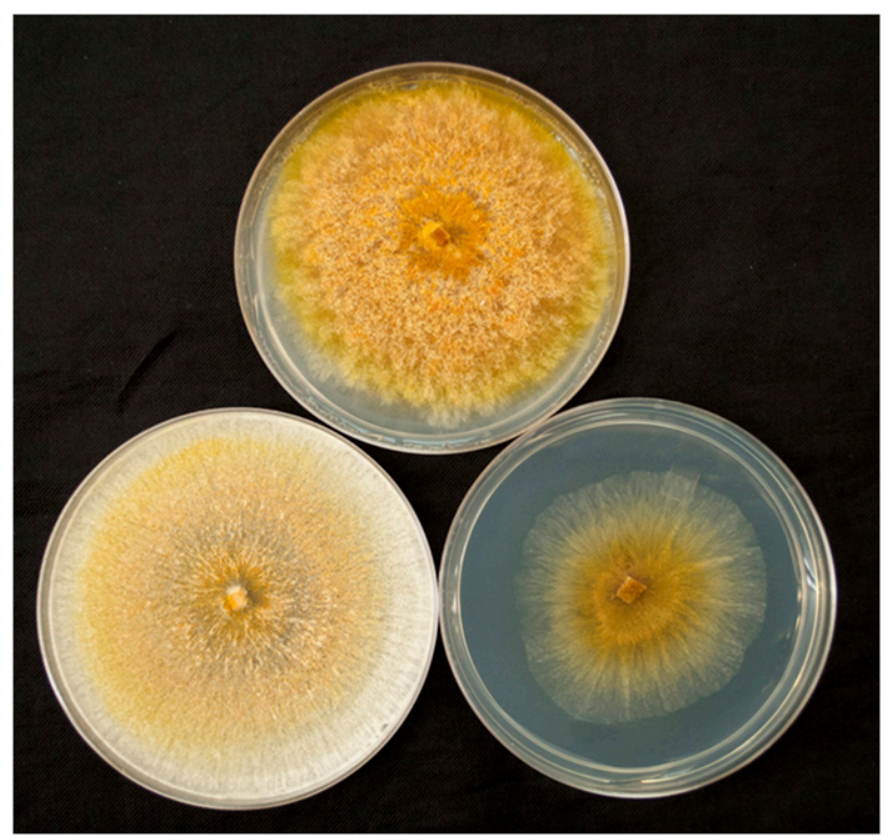

Fig. 1. Morphology of Wisconsin 25-1 virulent (top), Wisconsin 25-1 (CHV-1/ EURO7) (lower left), and Wisconsin 25-1 (CHV-3/COLI 11-1) (lower right) isolates of Cryphonectria parasitica grown on potato dextrose agar.

TABLE 1. Culture characteristics and pathogenicity of Cryphonectria parasitica isolates and hypoviruses pertinent to this study

\begin{tabular}{|c|c|c|c|c|}
\hline Strain designation & Fungal isolate & Hypovirus & Culture characteristics & Pathogenicity \\
\hline WS $-1^{\mathrm{a}}$ & Wisc. 25-1 & None & Fast growth, orange & Virulent \\
\hline WS- $2^{\mathrm{a}}$ & Wisc. 108-1 & None & Fast growth, orange & Virulent \\
\hline WS $-3^{\mathrm{a}}$ & Wisc. 133-1 & None & Fast growth, orange & Virulent \\
\hline WS-1 (COLI) & Wisc. $25-1$ & CHV-3/COLI 11-1 & Slow growth, orange & Hypovirulent \\
\hline WS-1 (EURO7) & Wisc. 25-1 & CHV-1/EURO7 & Fast growth, white & Moderately hypovirulent \\
\hline WS-2 (EURO7) & Wisc. 108-1 & CHV-1/EURO7 & Fast growth, white & $\mathrm{ND}^{\mathrm{b}}$ \\
\hline WS-3 (EURO7) & Wisc. 133-1 & CHV-1/EURO7 & Fast growth, white & ND \\
\hline \multicolumn{5}{|c|}{ Sources of hypovirus } \\
\hline COLI & COLI 11-1 & CHV-3/COLI 11-1 & Slow growth, orange & Hypovirulent \\
\hline EURO7 & EURO7 & CHV-1/EURO7 & Fast growth, white & Moderately hypovirulent \\
\hline
\end{tabular}

a WS-1, WS-2, and WS-3 are vegetatively incompatible.

b Not determined. 
slurry of WS-1 (CHV-3/COLI) was used to treat newly discovered cankers (from the base to $3.7 \mathrm{~m}$ off the ground) using the margin-punch method of inoculation (Bell 2004; Grente and Berthelay-Sauret 1978) The WS-1 (CHV-3/COLI) slurry was made by combining 20 PDA plates of 7- to 10-day-old cultures of WS-1 (CHV-3/COLI), 1.5 liter of sterile water and 1 liter of solidified sterile water agar (2.5\%). Ingredients were blended for $1 \mathrm{~min}$ in a 4-liter stainless steel Waring commercial blender. Similar slurries were made for WS-2 (CHV-1/ EURO7) and WS-3 (CHV-1/EURO7) inoculum that were used for the following treatment periods: 1995 to 1997 and from 2004 to 2014. Newly discovered cankers (2004 to 2014) were treated initially with WS-1 (CHV-1/EURO7). In subsequent years, when VC testing of strains from bark samples revealed that the canker was incited by strains representing WS-2 or WS-3, cankers were treated with either WS-2 (CHV-1/EURO7) or WS-3 (CHV-1/EURO7) based on the previous year's VC testing. In an attempt to discern if hypoviruses were able to disseminate without continual application, there was no hypovirus treatment from 1998 to 2003; however, we continued to sample bark plugs from all existing and new cankers. Professional tree climbers were hired to sample and treat cankers above $3.7 \mathrm{~m}$ in 1996 to 1997 and 2004 to 2005 . When cankers merged with one another, they typically were treated as a single merged unit rather than as individual cankers. Trees were designated dead when there were no living epicormic sprouts on the main stem or root sprouts from the base of the tree.

Permanent plots. The 2000 disease survey revealed that disease progress exceeded our ability to sample all infected trees. This situation resulted in the establishment of 12 permanent plots in 2001 representing differing levels of disease incidence in the stand (Fig. 2). Approximately $80 \%$ of the trees, infected by 2000 , fell into the 12 permanent plots. Plots 2, 3, 4, and 6 were in the area of the stand where

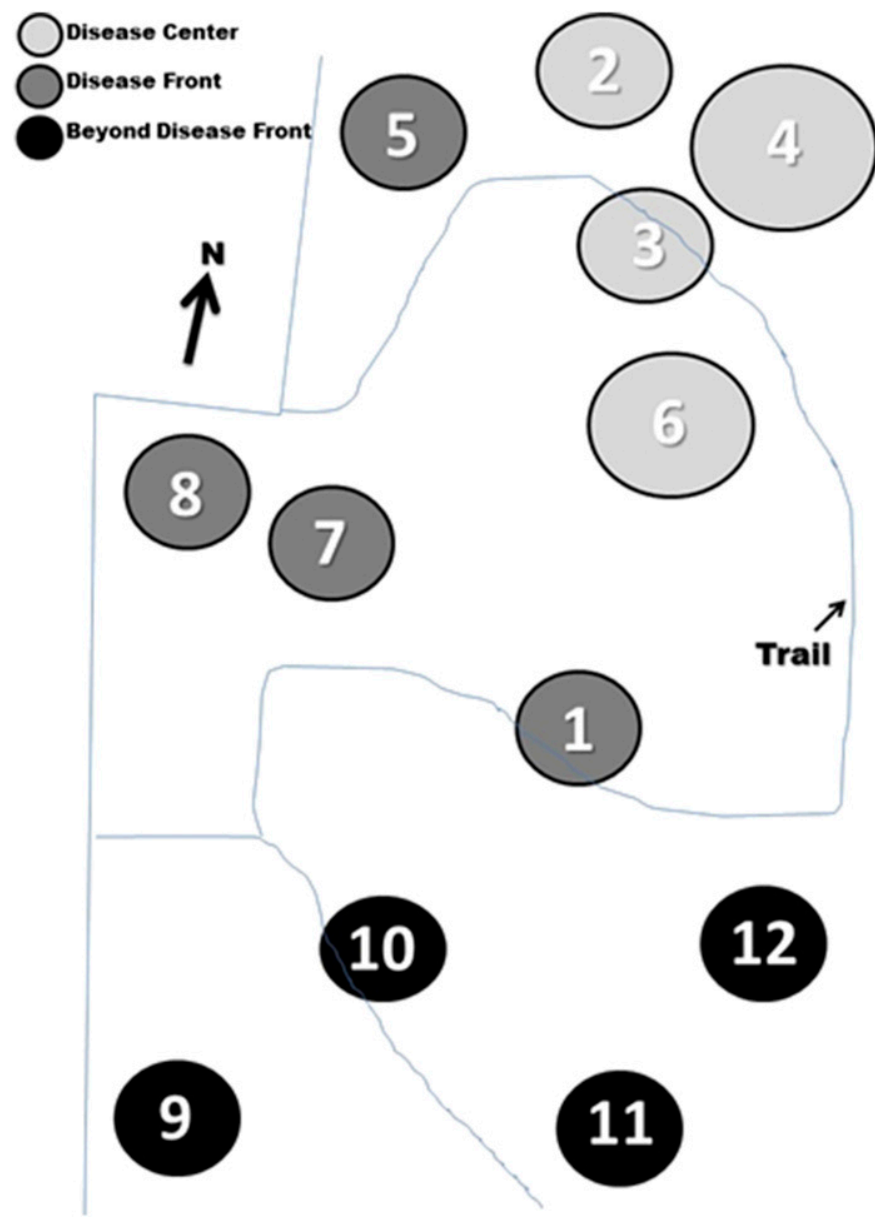

Fig. 2. Map of chestnut stand at West Salem, Wisconsin. The 12 plots that were initiated in 2001 are indicated by plot number. The Disease Center encompasses plots 2, 3, 4, and 6 . the disease was first discovered in 1987, subsequently referred to as the Disease Center. When the plots were established, two-thirds of the trees in each plot were designated to receive hypovirus treatment. The remaining one-third of the trees were not treated and used to assess tree-to-tree hypovirus dissemination. When a main stem died, resulting sprouts $(\geq 2.5 \mathrm{~cm})$ were treated similarly to the main stem. The results discussed in this paper represent data collected from the four Disease Center plots (2, 3, 4, and 6) (Fig. 2).

Canker rating and tree health assessment. All treated and nontreated cankers were rated annually from 1998 to 2014 using a 1 to 4 scale, where: 1 (best host response) = heavy callus with no sporulation; $2=$ heavy callus with limited sporulation; $3=$ slight-to-moderate callus with moderate-to-heavy sporulation; and 4 (poor host response) $=$ no callus and heavy sporulation. Additionally, the main stem of each tree was assessed annually from 2001 to 2014 and used to characterize the long-term recovery of trees treated with hypovirus compared with nontreated control trees. Trees were rated on a 1 to 5 scale, modified from Davelos and Jarosz (2004) where $1=$ main stem died due to blight infection, tree resprouting; $2=$ tree infected with only virulentappearing cankers (cankers rated 3 or 4 ); $3=$ tree infected with a combination of callousing (cankers rated 1 or 2 ) and virulent cankers; $4=$ tree infected with only callousing cankers; and $5=$ tree has never been infected (healthy with no crown dieback).

Two cohorts of trees were assessed. The first cohort (59 trees) included all trees infected between 1992 and 1997 that were treated with hypovirus (CHV3 and CHV1) in either the first or second year after infections were detected. The second cohort (61 trees) included trees initially infected between 1998 and 2003 that were not treated with hypovirus (CHV1) until at least 2004 (Fig. 3).

Analyses. All statistical analyses were conducted using SAS 9.3. In the analyses described below, hypovirus incidence is defined as the proportion of cankers that had at least one out of 12 isolates per canker from bark plugs showing infection by hypovirus. The proportion out of the 12 isolates per canker that showed infection by hypovirus is expressed as hypovirus frequency. Correlations between ranked canker ratings and frequency of hypovirulent isolates within a canker were evaluated using Spearman's rank test (PROC CORR). Differences among mean rating categories were compared by analysis of variance (ANOVA) (PROC GLM). Significant differences among means were determined with least significant differences. The frequency of hypovirulent isolates found in a canker (out of 12 samples per canker) was compared with a binomial model (PROC GENMOD) (Agresti 2002; Schabenberger and Pierce 2002). Significant differences were determined with the likelihood ratio statistic. The analysis of 2-year-old cankers was carried out using PROC GLM and significant differences among means were determined using Tukey's test.

\section{RESULTS}

VC type designation and diversity. All C. parasitica strains, isolated from cankers in the stand prior to 1991, were a single VC type, designated WS-1. As disease developed in the stand, two additional VC types were identified. These new VC types were designated WS-2 and WS-3. Additional VC types detected over the course of the study were designated WS-4 through WS-15. WS-1, the initial VC type to infect chestnuts in the stand, was the only VC type detected in the Disease Center prior to 1999 (Table 2), and has remained the predominate VC type. WS-2, was first detected in a portion of the stand distant $(\sim 1,000 \mathrm{~m})$ from the Disease Center in 1995, but not in the Disease Center until 1999. While WS-2 was detected every year thereafter, its frequency never rose above $6 \%$ (Table 2). WS-3, the third group, found in another portion of the stand ( $\sim 600 \mathrm{~m}$ from the Disease Center) in 1997, was not found in the Disease Center until 2005. The frequency of WS-3 never exceeded $2 \%$ in the Disease Center (Table 2). The mating type of WS1 and WS-3 is MAT1-2 while WS-2 is MAT1-1 (McGuire et al. 2004). Despite the discovery of 15 different VC during the study, 
WS-1 remained the most commonly isolated VC group in the Disease Center. Its frequency exceeded $80 \%$ each year (Table 2).

Disease incidence and canker dynamics. Disease incidence (i.e., proportion of trees infected), in the four Disease Center plots, increased steadily from 1992 so that by 2014,127 of the 128 monitored trees in the Disease Center plots were infected. The cumulative number of cankers detected over time displayed a nearly logistic pattern (Fig. 3, black bars). As the epidemic progressed in the 1990 s, the proportion of cankers treated with hypovirus decreased steadily after 1997 (Fig. 3). When treatments resumed in 2004, the number of cankers treated in the Disease Center remained low because limb dieback in the larger trees prevented efforts of tree climbers to treat cankers safely in the crowns of trees. In addition, a decrease in the number of sampled cankers over time was not necessarily solely the result of tree death. As hypovirulent cankers slow the growth of the infecting fungus, tree survivorship is lengthened and, over time, cankers often merged with each other so that they were no longer assessed as individual infections, but as merged units. As of 2014, 27\% of the 1,600 cankers in the four Disease Center plots had merged (data not shown).

Discernment of hypoviruses. CHV-1/EURO7 and CHV-3/ COLI were distinct morphologically (Fig. 1) and electrophoretically. The genome sizes were approximately 12.7 and $9.8 \mathrm{~kb}$, respectively, for $\mathrm{CHV}-1 / \mathrm{EURO} 7$ and $\mathrm{CHV}-3 / \mathrm{COLI}$.

Hypovirus incidence in cankers over time. When hypovirus incidence in treated cankers was assessed first in 1994, the CHV-3/COLI hypovirus was found in 55\% of the cankers to which hypovirulent inoculum had been introduced in 1992 and 1993. However, the CHV-3/COLI hypovirus was detected in only $15 \%$ of newly discovered cankers on treated trees in 1993 (Table 3). CHV-1/ EURO7 was selected as a less debilitating hypovirus when infecting the West Salem strain of $C$. parasitica. CHV-1/EURO7-infected strains also colonized more bark and produced more conidia in situ (Chen and Nuss 1999). Additionally, 93\% of conidia from WS-1 (CHV-1/EURO7) strains contained the CHV-1/EURO7 hypovirus in vitro, compared with $3 \%$ hypovirus for $\mathrm{CHV}-3 / \mathrm{COLI}$ conidia (data not shown). Replacement of CHV-3/COLI with CHV-1/
EURO7 in 1995 resulted in hypovirus detections in $78 \%$ of treated cankers and from $55 \%$ of nontreated cankers on treated trees by 1997 (Table 3). While spread on treated trees increased from 1995 to 1997 with the deployment of CHV-1/EURO7, tree-to-tree spread was only $10 \%$ in 1997 (Table 3). In the absence of hypovirus introductions from 1998 to 2003, tree-to-tree spread dropped to 2\% (Table 3). When CHV-1/EURO7 was reintroduced in 2005 and continued annually through 2014 , there was an increase in hypovirus incidence on nontreated trees from $53 \%$ in 2005 to $84 \%$ in 2014 (Table 3). A corresponding increase in hypovirus-infected strains isolated from bark plugs on nontreated trees increased from $6 \%$ in 2001 to $51 \%$ in 2014 (Fig. 4). Although CHV-3/COLI hypovirus has not been introduced as treatment inoculum since 1994, it still was detected from $1 \%$ of the bark isolates in 2014 (data not shown).

Hypovirus frequency within cankers. The twelve samples obtained from a canker in any given year revealed that most cankers yielded a variety of organisms including $C$. parasitica without hypovirus (virulent, V), isolates with hypovirus (HV), and fungi other than $C$. parasitica (non- $C$. parasitica $=$ non-C.p.) (Fig. 4). There were significant differences among the years in the proportion of isolates that were classified as V, HV, or non-C.p. $\left(\chi^{2}=1,106.78\right.$, df $=8, P<0.0001$ ) with $\mathrm{V}$ isolates decreasing and $\mathrm{HV}$ isolates increasing over time. There was a significantly greater proportion of $\mathrm{HV}$ and non-C.p. isolates found in cankers on treated trees than on nontreated trees $\left(\chi^{2}=1,039.80, \mathrm{df}=2, P<0.0001\right)$; additionally, the proportion of $\mathrm{V}$ isolates from cankers on nontreated trees was more than triple the proportion found from cankers on treated trees (data not shown).

Our annual sampling of individual cankers detected a shift in the fungi that were isolated (Table 4). Isolations from cankers treated between 1992 to 2000 were comprised of nearly equal numbers $(\sim 30 \%)$ of $\mathrm{V}$ and HV and non-C.p. (Table 4). The 271 cankers initially detected in 2001 were dominated by $\mathrm{V}$ isolates $(78 \%)$ (Table 4). Over the period of 2001 to 2014 , the fungi isolated from these cankers changed. The number of $\mathrm{V}$ isolates decreased (from 78 to $28 \%$ ); the hypovirus-containing isolates increased (6 to $36 \%$ ) and the number of samples yielding non-C.p. increased (16 to $36 \%)$.

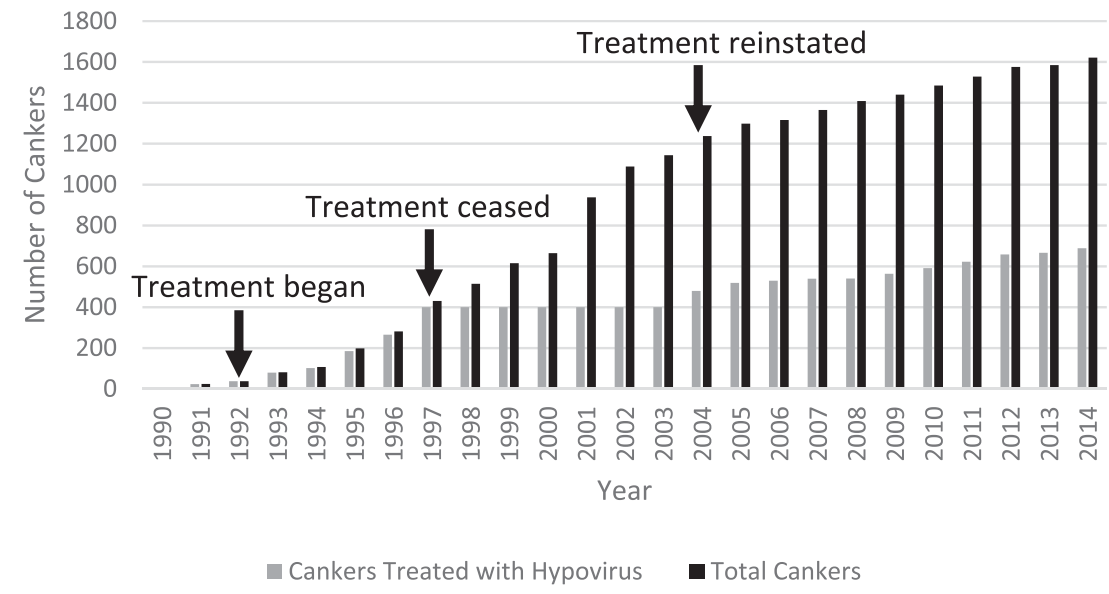

Fig. 3. Cumulative number of cankers (black bars) and number of cankers treated with hypovirus (gray bars) in the Disease Center over time.

TABLE 2. Percentage of Cryphonectria parasitica isolates in each of the three major vegetative compatibility groups (VCG) from 1994 to 2014 (1994 to 2000 includes all trees in the stand; 2001 to 2014 includes trees only in the Disease Center plots) ${ }^{\mathrm{a}}$

\begin{tabular}{|c|c|c|c|c|c|c|c|c|c|c|c|c|c|c|c|c|c|c|}
\hline \multirow[b]{2}{*}{ VCG } & \multicolumn{18}{|c|}{ Year } \\
\hline & 94 & 95 & 96 & 97 & 98 & 99 & 00 & 01 & 02 & 04 & 05 & 06 & 07 & 09 & 11 & 12 & 13 & $\overline{14}$ \\
\hline WS-1 & 100 & 100 & 100 & 100 & 100 & 95 & 94 & 97 & 99 & 98 & 92 & 96 & 95 & 84 & 94 & 89 & 92 & 88 \\
\hline WS-3 & 0 & 0 & 0 & 0 & 0 & 0 & 0 & 0 & 0 & 0 & 2 & 0 & 0 & 1 & 2 & 2 & $<1$ & 1 \\
\hline Number tested & 49 & 193 & 207 & 236 & 85 & 253 & 124 & 507 & 464 & 380 & 281 & 207 & 218 & 191 & 153 & 151 & 187 & 137 \\
\hline
\end{tabular}

a Total number of cankers tested in each year is presented. Trees within the Disease Center plots were not sampled in 2003, 2008, or 2010. 
Canker ratings and hypovirus incidence. In 2000, 29\% of cankers in the Disease Center were rated as 1 (Table 5). This type of canker expanded slowly or not at all and rarely girdled infected stems. The same year, the frequency of cankers rated as 4 with abundant stroma and no host callus was $32 \%$. The distribution of ratings changed over time; $20 \%$ more cankers were rated as 1 in 2014 than in 2000 and $23 \%$ fewer cankers rated as $4\left(\chi^{2}=20.83\right.$, df $=$ $6, P<0.002$; Table 5). When the relationship between canker ratings and hypovirus incidence was examined, there was no difference among years $\left(\chi^{2}=1.85, \mathrm{df}=2, \mathrm{~N} . \mathrm{S}\right.$.) (Table 5). Hypovirus incidence tended to be higher in cankers rated as a 1, but statistically, hypovirus incidence was not the highest in cankers rated 1 and lowest incidence in cankers rated $4\left(\chi^{2}=5.61, \mathrm{df}=3, \mathrm{~N} . \mathrm{S}\right.$. $)$. However, the canker rating system was correlated with the frequency of hypovirus detected within a canker (percentage of isolates out of 12) over all years $\left(r_{s}=-0.16, P<0.002\right)$ indicating that isolates associated with cankers rated 1 (abundant callus and no stroma) support more hypovirus than cankers rated 4 (no callus and abundant stroma) (Table 5).

The number of hypovirulent isolates recovered from bark plugs from cankers on treated trees were similar for cankers rated 1 through 3 (Table 6). Conversely, from cankers on nontreated trees, there was a distinct difference of recovery of hypovirulent isolates between cankers rated 1 or 2 (20 and 21\%) compared with cankers rated 3 or 4 (9 and 6\%) (Table 6). Recovery of non- $C$. parasitica isolates was greatest from cankers rated 1 on both treated and nontreated trees (Table 6).

One goal of this work was to determine if hypovirus treatments influenced future canker ratings. Our analysis found that over the course of the study, the rating of 2-year-old cankers was influenced by three factors: (i) rating of the canker in year one; (ii) treatment with hypovirus in year one; and (iii) whether the tree containing the new canker had cankers that were treated previously with hypovirus (Table 7). Generally, ratings for 2-year-old cankers were lowest for cankers that had a 1 rating in the first year, were treated with hypovirus that first year, and the tree had been treated previously with hypovirus.

Tree health. When the impact of hypovirus on tree health was assessed, by comparing cohorts of trees with and without hypovirus, $93 \%$ of the main stems from trees in the 1998 to 2003 cohort died back by 2009 , while only $47 \%$ of trees in the 1992 to 1997 cohort experienced main stem dieback (data not shown). Whole tree assessment showed that the proportion of trees alive in 2014 for the treated 1992 to 1997 cohort was $51 \%$ compared with only $31 \%$ for the nontreated 1998 to 2003 cohort. The condition of the 1992 to 1997 cohort is even more remarkable given that they were infected for a longer period of time ( 6 to 11 years) and they still had lower main stem dieback and tree mortality than the 1998 to 2003 cohort.

\section{DISCUSSION}

The biological control of chestnut blight in many areas of Europe has been attributed to the association of hypoviruses with infecting strains of C. parasitica (Heiniger and Rigling 1994; Robin and Heiniger 2001). In North America, despite some short-term success, there has been little or no biological control of blighted populations of American chestnut in the natural range of this species (Griffin 1999). Several factors have been proposed to explain the inability of hypoviruses to control blight in North America. They included the greater diversity of strains that exist in North American in contrast to localized areas in Europe (Anagnostakis et al. 1986; Cortesi and Milgroom 1998; Dutech et al. 2012; Robin and Heiniger 2001), a factor that likely impedes the transmission of hypovirus among strains (Liu and Milgroom 1996). Further, European chestnut, while susceptible to infection, is considered less so than American (Graves 1950; Hebard 1982). This difference in susceptibility may allow a longer period for cankers on European chestnut to become hypovirus infected. Despite these seemingly potential constraints, hypoviruses have spread throughout a number of blightinfected stands in Michigan (Day et al. 1977; Elliston et al. 1977; Fulbright et al. 1983), and demographic analyses have confirmed that the increase in growth and survivorship has resulted in ecological recovery at several Michigan sites whereby chestnut trees at several sites have reestablished their crowns and have regained canopy status (Davelos and Jarosz 2004). One possible explanation for recovering chestnut populations at several sites in Michigan may be that hypoviruses reduce sexual reproduction in $C$. parasitica, thus lowering VC diversity (Springer et al. 2013).

The biocontrol of chestnut blight with hypovirus was undertaken at the West Salem stand because a number of features of the epidemic at the site were similar to those in recovering Michigan stands: only a single VC strain of the pathogen was detected initially; the stand was isolated; and the chestnuts were known to be growing vigorously (Cummings Carlson et al. 1998; McEwan et al. 2006; Paillet and Rutter 1989). Unfortunately, as with the North American chestnut epidemic a century before, the disease progressed at West Salem so rapidly that by 2014 almost all individuals were infected. The initial goal of the project was to study the West Salem epidemic and in the process determine if we could mitigate the epidemic by treating infections with hypovirus-laden strains of the fungus. We accomplished the goal of treating the majority of reachable cankers through 1999. As the disease progressed, by 2000, the increasing epidemic overwhelmed our ability to treat all cankers in the stand (Fig. 3), thus necessitating the establishment of permanent plots in 2001 in areas of the stand representing various levels of disease (Fig. 2). Establishing plots enabled us to monitor the epidemic while treating a more realistic number of infections on trees within the plots. We ceased treating trees for a 6-year period (1998 to 2003) to monitor the epidemic and assess the effect of the 1992 to 1997 hypovirus treatment on disease progress. Although the level of canker control as measured by the cessation of their expansion was notable, new infections continued to develop annually.

During the study, two hypoviruses were deployed, both in the resident WS-1 background. The CHV-3/COLI hypovirus successfully slowed the growth of virulent strains but its ability to spread was not documented by our bark isolations in 1994 (Table 3). This led to the deployment of a second hypovirus in 1995, CHV-1/ EURO7, that had demonstrated its ability to spread among cankers within infected trees, based on previous field studies (Hobbins et al. 1994; Jakobi 2005). Chen and Nuss (1999) found that field strains infected with CHV-1/Euro7 were more virulent and exhibited less

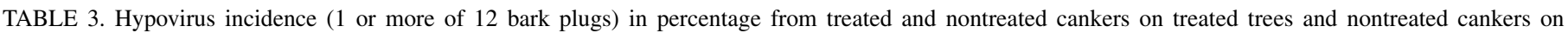
nontreated trees in the Disease Center over time

\begin{tabular}{|c|c|c|c|c|c|c|c|}
\hline Canker treatment & $1994^{\mathrm{ab}}$ & $1997^{\mathrm{ac}}$ & $2002^{c}$ & $2005^{\mathrm{d}}$ & $2007^{d}$ & $2011^{\mathrm{d}}$ & $2014^{\mathrm{d}}$ \\
\hline Treated cankers on treated trees & $55^{\mathrm{e}}(66)$ & $78(252)$ & $80(147)$ & $78(156)$ & $86(100)$ & $85(78)$ & $86(47)$ \\
\hline Nontreated cankers on treated trees & $29(31)$ & $55(120)$ & $30(167)$ & $77(111)$ & $83(53)$ & $61(54)$ & $72(47)$ \\
\hline Nontreated cankers on nontreated trees & $15(7)$ & $10(72)$ & $2(58)$ & $53(34)$ & $51(53)$ & $76(54)$ & $84(46)$ \\
\hline
\end{tabular}

a Includes trees before the establishment of permanent plots.

b CHV-3/COLI hypovirus deployed.

c No hypovirus treatment 1998 to 2003.

d CHV-1/EURO7 hypovirus deployed.

e First number is the percentage of the total tested and the number in parentheses is the number of cankers tested. 
severe phenotypic changes (hypovirulence-associated traits) than strains infected with the prototypic hypovirus CHV-1/EP713. Unfortunately, spatial data suggested that the spread of CHV-1/EURO7, while better than the $\mathrm{CHV}-3 / \mathrm{COLI}$, did not spread as readily as the resident virulent strain of $C$. parasitica (Jarosz et al. 2002).
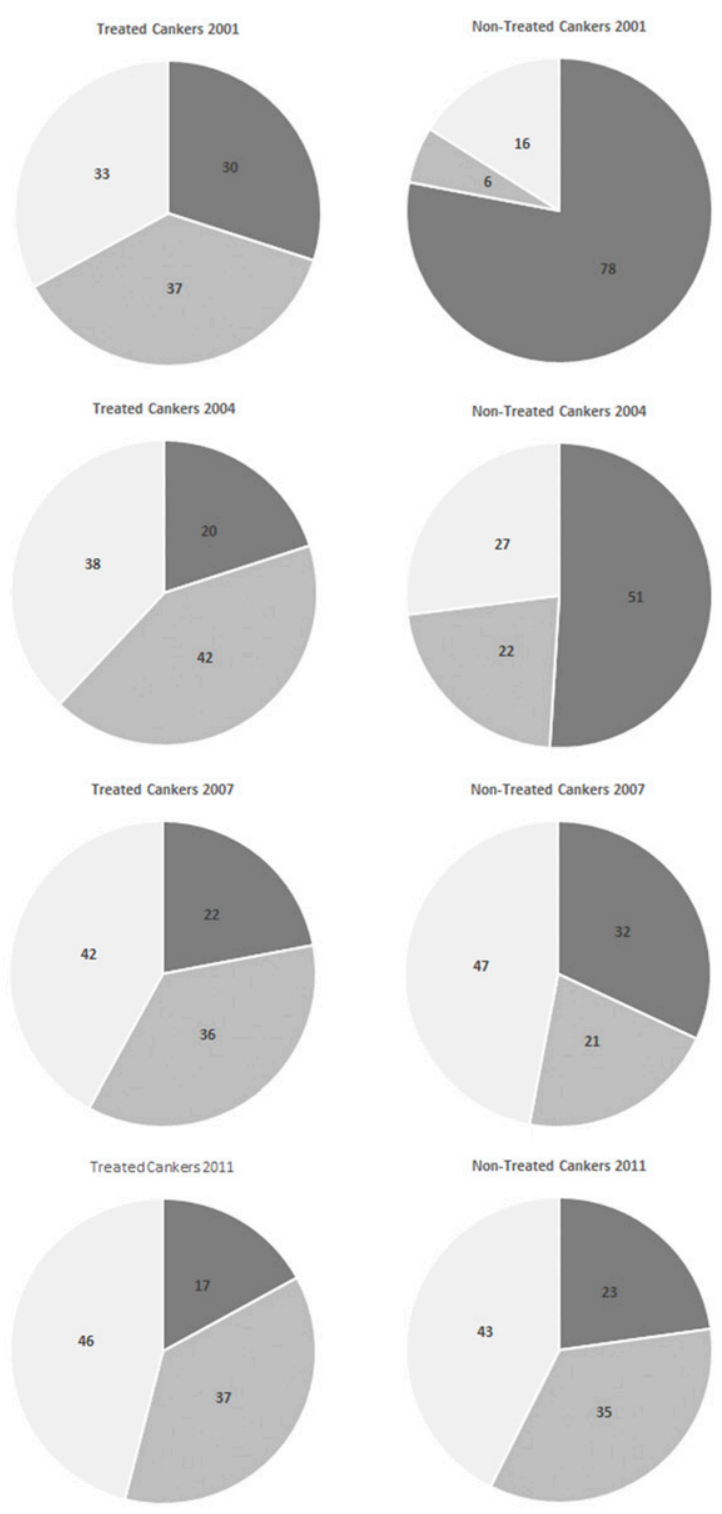

Non-Treated Cankers 2011
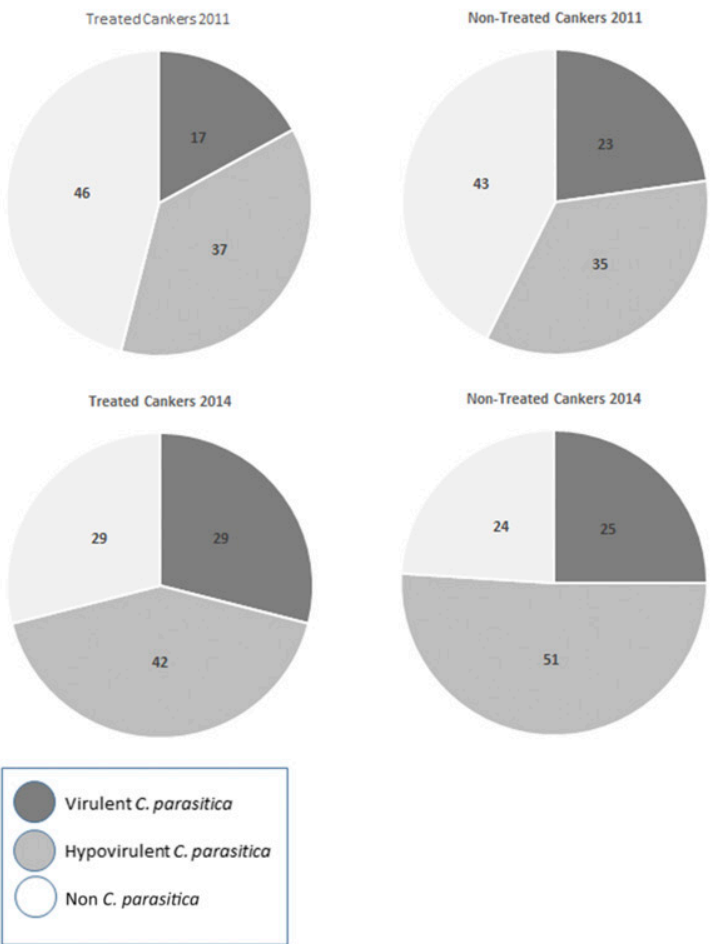

Fig. 4. Percentage of virulent and hypovirulent Cryphonectria parasitica and non- $C$. parasitica isolates from bark plugs in different years. Left column represents cankers from treated trees and the right column represents nontreated trees.
For hypovirus-mediated biological control of chestnut blight to be successful, four criteria have been proposed: (i) presence, persistence, and spread of hypoviruses; (ii) reductions in disease incidence or disease virulence; (iii) increase in tree growth and survival; and (iv) increase in productivity of marketable products such as lumber or nuts (Milgroom and Cortesi 2004).

The increasing incidence of detectable hypovirus infection over time, even when hypovirus introductions were suspended, indicates that hypoviruses are well established in the Disease Center portion of the stand. The dissemination of hypoviruses is supported by the spread of hypoviruses to new cankers on treated trees and those on untreated trees, but not until 2005, after the CHV-1/EURO7 hypovirus was deployed for a second time (Table 3 ). Of the 81 new, untreated cankers in the Disease Center observed between 2011 to 2014, 86\% harbored this hypovirus (data not shown). Further, when hypovirus frequency is considered, persistence and spread of hypovirus is even greater in nontreated cankers (Fig. 4). The percentage of isolates with hypovirus recovered from treated cankers remained relatively stable from 2002 through 2014 ( $~ 80 \%)$, whereas isolates with hypovirus from nontreated cankers increased dramatically

TABLE 4. Percentage of virulent and hypovirulent Cryphonectria parasitica and non- $C$. parasitica isolates from a set of new cankers detected in 2001 on nontreated trees and previously treated cankers (1992 to 1997) on treated trees, sampled over time

\begin{tabular}{lcccc}
\hline Year & $N^{\mathrm{a}}$ & $\%$ Virulent & $\%$ Hypovirulent & $\%$ Non-C. parasitica \\
\hline \multicolumn{5}{l}{ rew cankers detected in } \\
2001 & 271 & $78 \%$ & on nontreated trees \\
2004 & 93 & $47 \%$ & $6 \%$ & $16 \%$ \\
2007 & 39 & $31 \%$ & $21 \%$ & $32 \%$ \\
2011 & 21 & $22 \%$ & $21 \%$ & $48 \%$ \\
2014 & 18 & $28 \%$ & $34 \%$ & $43 \%$ \\
Previously treated cankers (from 1992 to 1997$)$ & $36 \%$ \\
2001 & 343 & $35 \%$ & $37 \%$ & \\
2004 & 145 & $20 \%$ & $35 \%$ & $38 \%$ \\
2007 & 61 & $20 \%$ & $33 \%$ & $45 \%$ \\
2011 & 44 & $18 \%$ & $32 \%$ & $50 \%$ \\
2014 & 32 & $29 \%$ & $42 \%$ & $29 \%$ \\
\hline
\end{tabular}

${ }^{a} N$ is the number of samples tested.

TABLE 5. Canker rating, percentage of cankers in each rating class by year, hypovirus incidence (percentage of cankers having at least 1 of 12 isolates with hypovirus), and frequency of virulent, hypovirulent Cryphonectria parasitica, and non- $C$. parasitica (based on 12 samples/canker) for years 2000, 2009, and 2014 in the Disease Center

\begin{tabular}{|c|c|c|c|c|c|c|}
\hline \multirow[b]{2}{*}{ Year } & \multirow[b]{2}{*}{$\begin{array}{l}\text { Canker } \\
\text { rating }\end{array}$} & \multirow[b]{2}{*}{$\begin{array}{l}\% \text { Total } \\
\text { cankers }^{b}\end{array}$} & \multirow{2}{*}{$\begin{array}{c}\text { Hypovirus } \\
\text { incidence } \\
(\%)^{c}\end{array}$} & \multicolumn{3}{|c|}{$\begin{array}{c}\text { Percent bark samples } \\
\text { based on } 12 \text { samples/canker }\end{array}$} \\
\hline & & & & Virulent & Hypovirulent & $\begin{array}{l}\% \text { Non- } \\
\text { C. } \text { parasitica }^{\mathrm{d}}\end{array}$ \\
\hline \multirow[t]{4}{*}{2000} & 1 & 29 & 72 & $17 \%$ & $29 \%$ & $54 \%$ \\
\hline & 2 & 21 & 56 & $51 \%$ & $20 \%$ & $29 \%$ \\
\hline & 3 & 18 & 43 & $65 \%$ & $15 \%$ & $20 \%$ \\
\hline & 4 & 32 & 30 & $55 \%$ & $18 \%$ & $27 \%$ \\
\hline \multirow[t]{4}{*}{2009} & 1 & 36 & 67 & $21 \%$ & $25 \%$ & $54 \%$ \\
\hline & 2 & 22 & 53 & $36 \%$ & $17 \%$ & $47 \%$ \\
\hline & 3 & 21 & 50 & $53 \%$ & $16 \%$ & $31 \%$ \\
\hline & 4 & 22 & 47 & $49 \%$ & $12 \%$ & $39 \%$ \\
\hline \multirow[t]{4}{*}{2014} & 1 & 49 & 83 & $24 \%$ & $40 \%$ & $36 \%$ \\
\hline & 2 & 28 & 75 & $40 \%$ & $42 \%$ & $18 \%$ \\
\hline & 3 & 14 & 69 & $43 \%$ & $35 \%$ & $22 \%$ \\
\hline & 4 & 9 & 33 & $65 \%$ & $11 \%$ & $24 \%$ \\
\hline
\end{tabular}

a Canker rating: 1 (best host response) = heavy callus with no sporulation; $2=$ heavy callus with limited sporulation; 3 = slight-to-moderate callus with moderate-to-heavy sporulation; and 4 (poor host response) $=$ no callus and heavy sporulation.

b Total cankers by year: $2000(N=170), 2009(N=462)$, and $2014(N=204)$.

c Percentage of cankers that contained one or more hypovirus-containing C. parasitica isolates.

${ }^{\mathrm{d}}$ Bark plugs yielding fungal isolates that were non-C. parasitica. 
from $2 \%$ in 2002 to $84 \%$ in 2014 (Table 3 ). The dissemination of the CHV-1/EURO7 hypovirus to nontreated trees eventually equaled that of treated trees, although that transition took more than a decade.

A second criterion used to measure the success of biocontrol using hypoviruses was canker morphology, an assessment of response of the host to reduced pathogen virulence. Cankers rated 1 or 2 (indicating less sporulation and greater callus production) had a lower frequency of virulent $C$. parasitica isolates associated with infections and a higher frequency of hypovirulent $C$. parasitica compared with cankers rated 3 or 4 (Tables 5 and 6 ). The majority of new cankers were rated as 3 or 4, suggesting that new cankers are initially virulent (Table 6). Two-year-old cankers, regardless of the year they were treated, were tested by ANOVA and the history of treatment had a significant effect on the morphology of subsequent cankers $(\mathrm{F}=4.06 ; P=0.0447$, Table 7$)$. However, the proportion of all cankers rated 1 or 2 increased from 50\% in 2000 to $77 \%$ in 2014 (Table 5). This difference in canker rating over time indicates that, in the Disease Center portion of the stand, there was a shift from more virulent, callus-free cankers to those with high amounts of callus and reduced sporulation, a result consistent with successful biological control, similar to other sites where hypovirulence is active.

The third approach used to evaluate the success of biological control was tree survival. The landowners requested the inoculation of all reachable cankers on every infected tree in exchange for allowing hypovirus introduction and annual monitoring of the stand. Thus, no control trees were available to compare survival of trees with and without hypovirus treatments from 1992 to 1997. This shortcoming was somewhat offset with the establishment of plots and the two cohorts of trees in the plots. A comparison was possible between a cohort of trees initially infected and treated with hypovirus between 1992 to 1997 and a cohort of trees that were infected between 1998 to 2003 and not treated with hypovirus until 2004. The number of surviving trees from the 1992 to 1997 cohort compared with the 1998 to 2003 cohort (51 and 31\%, respectively) suggests that hypovirus treatments had a positive effect on the tree survival. Indeed, several trees in the Disease Center have reestablished their crowns (developing new foliage) and have been producing burrs for several years (personal observation).

The final criterion proposed by Milgroom and Cortesi (2004) for successful biological control is the increase in productivity of marketable products such as lumber or nuts. For this stand, a more valuable criterion would be the successful recruitment of new seedlings that would allow the population to persist in the long term (Silvertown et al. 1996). While data on seedling recruitment is not yet available, Gilland et al. (2012) estimated $1.043 \times 10^{6}$ seeds would be produced per hectare from mature chestnut trees in the stand. Whether or not these nuts are marketable does not influence seedling recruitment and thus, the long-term persistence of this stand. However, annual mast production improves wildlife habitat (Anonymous 2009), increases survival and reproduction (Schnurr et al. 2002) and is a positive sign of biological control that may lead to perpetuation of the stand.

One often overlooked observation is that the majority of cankers in this stand contain a complex mixture of fungi including $C$. parasitica, with and without hypovirus, and numerous other fungi (non-C.p.) (Tables 4, 5, and 6; Fig. 4). Cankers that contain a mixture of virulent and hypovirulent isolates have been noted in European (Ćurković-
Perica et al. 2015; Turchetti et. al. 2008) and U.S. chestnut populations (Hogan and Griffin 2002). Such complex cankers also have been found in recovering stands in Michigan (Kolp et al. 2013; Schaupp et al. 1997).

All cankers, whether mainly virulent or hypovirulent, are a mixture of $C$. parasitica and other fungi. However, the frequency of other fungi recovered from cankers is much higher for hypovirulent than virulent cankers (cankers rated 1 and 2 versus 3 and 4) (Table 6). Our contention is that hypovirulent cankers simply survive longer, allowing for colonization by other organisms. There does not appear that there is an upper limit to the amount of hypovirus acquisition within a canker. Our data indicate that cankers with hypovirus are slowly invaded by secondary fungal colonists, mainly Trichoderma sp. along with Botryosphaeria sp., Didymostilbe spp., Penicillium spp., Paraconiothyrium spp., Epicoccum niger, Umbelopsis isabellina, and Pestalotiopsis spp. (Double et al. 2013). Similar results have been found for cankers on chestnuts growing in the Black Sea region of Turkey (Akilli et al. 2011), where a Trichoderma isolate was found to be as effective as hypovirulent isolates in controlling virulent cankers. The full containment of $C$. parasitica within a canker may involve both the action of hypovirus and other organisms that colonize bark previously invaded by $C$. parasitica. Earlier work in the eastern United States reported that Trichoderma spp. could be used to suppress C. parasitica within cankers (Tattar et al. 1996). At this point, the role secondary invaders play is unclear. Whether they are necessary for functional biological control of C. parasitica when hypoviruses are present is not understood. Our sampling was restricted to cankers on living trees. As such we did not sample cankers on dead trees that may harbor a vastly different constituency of secondary fungi.

The role of VC may have impacted the success of biological control in the stand. One reason for the successful spread of hypoviruses may be the result, in part, of the relatively low diversity of the $C$. parasitica population in the Disease Center. The first VC type found, WS-1, has remained the dominant VC type in the stand over the 23 years of this project (Table 2) while other areas of the stand had a more diverse VC structure (data not shown). Robin et al. (2009) state that a low diversity in $\mathrm{VC}$ types provides good opportunities for biocontrol with CHV-1 in areas of France and Spain. Our results for the Disease Center agree with this conclusion.

TABLE 7. Analysis of variance for 2-year-old cankers based on the influence of the canker rating in year one (Y1R), treatment of the canker in year one (TY1), and the history of hypovirus treatment for tree (TTH)

\begin{tabular}{lcccc}
\hline Source of variance & $\begin{array}{c}\text { Degrees of } \\
\text { freedom }\end{array}$ & $\begin{array}{c}\text { Mean } \\
\text { square }\end{array}$ & $F$ value & Significance \\
\hline $\begin{array}{l}\text { Year 1 rating (Y1R) } \\
\text { Treatment in year 1 }\end{array}$ & 3 & 13.49 & 17.93 & $<0.0001$ \\
$\quad$ (TY1: yes or no) & 1 & 6.12 & 8.26 & 0.0043 \\
$\begin{array}{l}\text { Y1R by TY1 interaction } \\
\text { Tree previously treated }\end{array}$ & 3 & 0.68 & 0.91 & 0.4380 \\
$\quad$ with hypovirus (TTH: & & & & \\
$\quad$ yes or no) & 1 & 3.05 & 4.06 & 0.0447 \\
Y1R by TTH interaction & 3 & 0.41 & 0.54 & 0.6528 \\
TY1 by TTH interaction & 1 & 2.31 & 3.07 & 0.0806 \\
Y1R by TY1 by TTH & & & & \\
$\quad$ interaction & 3 & 1.37 & 1.81 & 0.1439 \\
Error & 400 & & & \\
\hline
\end{tabular}

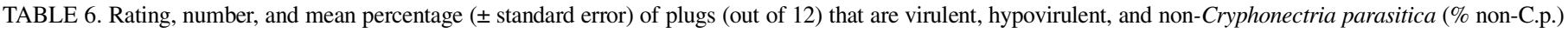
for first year Disease Center cankers (1998 to 2007) for previously treated and nontreated trees

\begin{tabular}{|c|c|c|c|c|c|c|c|c|}
\hline \multirow[b]{2}{*}{ Canker rating } & \multicolumn{4}{|c|}{ Treated trees } & \multicolumn{4}{|c|}{ Nontreated trees } \\
\hline & $N$ & $\%$ Virulent & \% Hypovirulent & $\%$ Non-C.p. & $N$ & $\%$ Virulent & $\%$ Hypovirulent & $\%$ Non-C.p. \\
\hline 1 & 48 & $23 \pm 3$ & $37 \pm 4$ & $40 \pm 4$ & 11 & $39 \pm 8$ & $29 \pm 10$ & $32 \pm 9$ \\
\hline 2 & 71 & $27 \pm 3$ & $45 \pm 4$ & $28 \pm 3$ & 23 & $51 \pm 7$ & $21 \pm 6$ & $28 \pm 5$ \\
\hline 3 & 75 & $41 \pm 4$ & $35 \pm 4$ & $24 \pm 3$ & 84 & $75 \pm 3$ & $9 \pm 2$ & $17 \pm 2$ \\
\hline 4 & 147 & $60 \pm 3$ & $20 \pm 2$ & $20 \pm 2$ & 190 & $79 \pm 2$ & $6 \pm 1$ & $15 \pm 1$ \\
\hline
\end{tabular}


This study introduced hypoviruses, followed their dissemination, and measured their effect on biological control of chestnut blight over the course of more than 20 years. It demonstrated that time is a critical factor to the successful expression of hypovirulence, as shown by the increase in hypovirulent isolates from cankers on nontreated trees from 2001 to 2014 (Table 5). The study involved the annual introduction of hypovirus to more than 1,600 cankers in the Disease Center. While evidence of biological control was seen almost immediately as individual treated cankers began to callous, 10 to 15 years passed before the extent of recovery appeared comparable to that observed in other areas where biological control is occurring naturally. We believe that recovery at the West Salem site could be artificially initiated because of the clonal nature of the original $C$. parasitica population. A situation comparable to this does not exist in the natural range of chestnut in eastern North America. At this point, we anticipate this portion of the stand will continue to recover even though the number of new VC types slowly are emerging that could restrict hypovirus transmission. Another important factor in biological control that we discovered over the course of this study was that secondary organisms are increasingly recovered from cankers as they callus and age. Many of these organisms are known antagonists and may play a role in the long-term success or failure of hypovirulence as a biological control.

\section{ACKNOWLEDGMENTS}

We thank the landowners Scott and Sherri Bockenauer (and the late Ron Bockenauer) and Karl and Debbie Rhyme (and the late Deloris Rhyme) for their permission to conduct this study. J. Cummings Carlson, S. Dahir, and K. Scanlon of the Wisconsin Department of Natural Resources were instrumental to the undertaking of this study; their help was invaluable. We thank the countless undergraduate and graduate students from Michigan State University and the University of Wisconsin La Crosse who participated in the annual treatment/ survey; L. Bartlett, B. Bell, J. Bright, G. Flamik, M. King, A. Kish, M. Malone, B. Mauser, S. McCawley, A. Metheny, E. Murphy, S. A. Naymick, E. Orlikoff, R. Rush, N. Sheets, S. Woodling, G. T. Wright, and A. Zondlo at West Virginia University who characterized the bark samples that were collected over the many years of this study; and S. Gere, K. Hamm, and L. Wallace, professional arborists, who assisted with sampling, treatment, and evaluation of cankers from the tree crowns.

\section{LITERATURE CITED}

Agresti, A. 2002. Categorical Data Analysis, 2nd ed. Wiley, New York.

Akilli, S., Katircioğlu, Y. K., and Maden, S. 2011. Biological control of chestnut canker, caused by Cryphonectria parasitica, by antagonistic organisms and hypovirulent strains. Turk. J. Agric. For. 35:515-523.

Anagnostakis, S. L. 1977. Vegetative incompatibility in Endothia parasitica. Exp. Mycol. 1:306-316.

Anagnostakis, S. L., Hau, B., and Kranz, J. 1986. Diversity of vegetative compatibility groups of Cryphonectria parasitica in Connecticut and Europe. Plant Dis. 70:536-538.

Anonymous. 2009. Managing woodlots for mast. Mast Tree Network. http:// www.mast-producing-trees.org/2009/11/managing-woodlots-for-mast

Bell, B. C. 2004. Comparison of chestnut canker treatment procedures for hypovirus introduction. M.S. thesis, West Virginia University, Morgantown.

Castro, M., Kramer, K., Valdivia, L., Ortiz, S., and Castillo, A. 2003. A double-stranded RNA mycovirus confers hypovirulence-associated traits to Botrytis cinerea. FEMS Microbiol. Lett. 228:87-91.

Chen, B., and Nuss, D. L. 1999. Infectious cDNA clone of hypovirus CHV1EURO7: A comparative virology approach to investigate virus-mediated hypovirulence of the chestnut blight fungus Cryphonectria parasitica. J. Virol. 73:985-992.

Clark, S. L., Schlarbaum, S. E., Saxton, A. M., and Hebard, F. V. 2016. Establishment of American chestnuts (Castanea dentata) bred for blight (Cryphonectria parasitica) resistance: Influence of breeding and nursery grading. New For. 47:243-270.

Cortesi, P., and Milgroom, M. G. 1998. Genetics of vegetative incompatibility in Cryphonectria parasitica. Appl. Environ. Microbiol. 64:2988-2994.

Cummings Carlson, J., Fulbright, D. W., MacDonald, W. L., and Milgroom, M. G. 1998. West Salem: A research update. J. Am. Chestnut Found. 12:24-26.

Ćurković-Perica, M., Ježić, M., Karin, V., Idžojtić, M., Sotirovski, K., Risteski, M., Rigling, D., Prospero, S., Kolp, M., and Double, M. 2015. Biological control of chestnut blight: Persistence of biocontrol agent Cryphonectria hypovirus 1 in healed chestnut canker. XVIII International Plant Protection Congress, Berlin, Germany.

Davelos, A. L., and Jarosz, A. M. 2004. Demography of American chestnut populations: Effects of pathogen and a hyperparasite. J. Ecol. 92:675-685.

Day, P. R., Dodds, J. A., Elliston, J. E., Jaynes, R. A., and Anagnostakis, S. L. 1977. Double-stranded RNA in Endothia parasitica. Phytopathology 67: 1393-1396.

Dutech, C., Barres, B., Bridier, L., Robin, C., Milgroom, M., and Ravignés, V. 2012. The chestnut blight fungus world tour: Successive introduction events from diverse origins in an invasive plant fungal pathogen. Mol. Ecol. 21: 3931-3946.

Doherty, M., Coutts, R. H. A., Brasier, C., and Buck, K. W. 2006. Sequence of RNA-dependent RNA polymerase genes provides evidence for three more distinct mitoviruses in Ophiostoma novo-ulmi isolate Ld. Virus Genes 33:41-44.

Double, M. L., Kolp, M. R., Jarosz, A. M., Davelos Baines, A., Fulbright, D. W., and MacDonald, W. L. 2013. Fungi associated with hypovirulent cankers of differing ages on American chestnut. Acta Hortic. 1043:57-65.

Elliston, J. E., Jaynes, R. A., Day, P. R., and Anagnostakis, S. L. 1977. A native American hypovirulent strain of Endothia parasitica. Proc. Am. Phytopathol. Soc. 4:83-84.

Fulbright, D. W., Weidlich, W. H., Haufler, K. Z., Thomas, C. S., and Paul, C. P. 1983. Chestnut blight and recovering American chestnut trees in Michigan. Can. J. Bot. 61:3164-3171.

Gilland, K. E., Keiffer, C. H., and McCarthy, B. C. 2012. Seed production of mature forest-grown American chestnut (Castanea dentata [Marsh.] Borkh). J. Torrey Bot. Soc. 139:283-289.

Graves, A. H. 1950. Relative blight resistance in species and hybrids of Castanea. Phytopathology 40:1125-1131.

Grente, J. 1981. Les variants hypovirulents de l'Endothia parasitica et la lutte biologique contre le chancre du châtaignier. Ph.D. dissertation, Univ. Bretagne Occid.

Grente, J., and Berthelay-Sauret, S. 1978. Biological control of chestnut blight in France. Pages 30-34 in: Proc. American Chestnut Symposium. W. L. MacDonald, F. C. Cech, J. Luchok, and C. Smith, eds. West Virginia University Press, Morgantown, WV.

Griffin, G. J. 1999. Frequencies and spatial patterns of white hypovirulent and pigmented strains of Cryphonectria parasitica within blight-controlled cankers on grafted American chestnut trees 15-16 years after inoculation. Eur. J. Forest Pathol. 29:377-390.

Griffin, G. J. 2000. Blight control and restoration of the American chestnut. J. For. 98:22-27.

Hebard, F. V. 1982. Biology of virulent and hypovirulent Endothia parasitica on American chestnut (Castanea dentata). Ph.D. dissert. Virginia Polytechnic Institute and State University, Blacksburg, VA.

Heiniger, U., and Rigling, D. 1994. Biological control of chestnut blight in Europe. Annu. Rev. Phytopathol. 32:581-599.

Hobbins, D. L., Double, M. L., Sypolt, C. R., and MacDonald, W. L. 1994. Interactions between artificially established virulent Cryphonectria parasitica cankers and sources of virulent and hypovirulent inoculum on American chestnut stems. Pages 56-160 in: Proc. International Chestnut Conference. M. L. Double and W. L. MacDonald, eds. West Virginia University Press, Morgantown, WV.

Hogan, E. P., and Griffin, G. J. 2002. Incomplete movement of Cryphonectria hypovirus 1 within a vegetative compatibility type of Cryphonectria parasitica in natural cankers on grafted American chestnut trees. For. Path. 32: 331-344.

Jakobi, S. R. 2005. Effects of hypovirulent Cryphonectria parasitica inoculum, developmental stages of cankers, and time of year of wounding on the survival of American chestnut. Ph.D. dissert., West Virginia University, Morgantown, WV.

Jarosz, A. M., Dahir, S. E., and Double, M. L. 2002. Spatial patterns of blight and hypovirus spread within the West Salem chestnut stand. (Abstr.) Phytopathology 92(suppl.):S94.

Kolp, M. R., Double, M., Fulbright, D. W., MacDonald, W. L., and Jarosz, A. M. 2013. Do secondary fungal invaders influence disease severity of chestnut blight on American chestnut? 98th Ecological Society of American Annual Meeting, Minneapolis, MN.

Kuhlman, E. G. 1978. The devastation of American chestnut by blight. Pages 1-3 in: Proc. American Chestnut Symposium. W. L. MacDonald, F. C. Cech, J. Luchok, and C. Smith, eds. West Virginia University Press, Morgantown, WV.

Liu, Y., and Milgroom, M. G. 1996. Correlation between hypovirus transmission and the number of vegetative incompatibility (vic) genes different among isolates from a natural population of Cryphonectria parasitica. Phytopathology 86:79-86.

MacDonald, W. L., and Fulbright, D. W. 1991. Biological control of chestnut blight: Use and limitations of transmissible hypovirulence. Plant Dis. 75: 653-661. 
McEwan, R. W., Keiffer, C. H., and McCarthy, B. C. 2006. Dendroecology of American chestnut in a disjunct strand of oak-chestnut forest. Can. J. For. Res. 36:1-11.

McGrath, C. 1992. The last stand chance? American chestnut stand in West Salem, Wisconsin. American Forests Nov-Dec.

McGuire, I. C., Davis, J. E., Double, M. L., MacDonald, W. L., Rauscher, T., McCawley, S., and Milgroom, M. G. 2005. Heterokaryon formation and parasexual recombination between vegetatively incompatible lineages in a population of the chestnut blight fungus, Cryphonectria parasitica. Mol. Ecol. 14:3657-3669.

McGuire, I. C., Marra, R. E., and Milgroom, M. G. 2004. Mating-type heterokaryosis and selfing in Cryphonectria parasitica. Fungal Genet. Biol. 41:521-533.

Milgroom, M. G. 1999. Viruses in fungal populations. Pages 283-305 in: Structure and Dynamics of Fungal Populations. J. J. Worrall, ed. Kluwer Academic, Dordrecht, the Netherlands.

Milgroom, M. G., and Cortesi, P. 2004. Biological control of chestnut blight with hypovirulence: A critical analysis. Annu. Rev. Phytopathol. 42:311-338.

Morris, T. J., and Dodds, J. A. 1979. Isolation and analysis of double-stranded RNA from virus-infected plant and fungal tissue. Phytopathology 69:854-858.

Muñoz-Adalia, E. J., Fernández, M. M., and Diez, J. J. 2016. The use of mycoviruses in the control of forest diseases. Biocontrol Sci. Technol. 26:577-604.

Nuss, D. L., and Hillman, B. I. 2011. Hypoviridae. Pages 1029-1034 in: Virus Taxonomy. A. M. Q. King, M. J. Adams, E. B. Carstens, and E. J. Lefkowitz, eds. Elsevier, Oxford, UK.

Paillet, F. L., and Rutter, P. A. 1989. Replacement of native oak and hickory tree species by the introduced American chestnut (Castanea dentata) in southwestern Wisconsin. Can. J. Bot. 67:3457-3469.

Pearson, M. N., Beever, R. E., Boine, B., and Arthur, K. 2009. Mycoviruses of filamentous fungi and their relevance to plant pathology. Mol. Plant Pathol. 10:115-128.

Peever, T. L., Liu, Y.-C., and Milgroom, M. G. 1997. Diversity of hypoviruses and other double-stranded RNAs in Cryphonectria parasitica in North America. Phytopathology 87:1026-1033.

Powell, W. A. 1995. Vegetative incompatibility and mycelial death of Cryphonectria parasitica detected with a $\mathrm{pH}$ indicator. Mycologia 87:738-741.
Robin, C., Capdevielle, X., Martin, M., Traver, C., and Colinas, C. 2009. Cryphonectria parasitica vegetative compatibility types analysis of populations in south-western France and northern Spain. Plant Pathol. 58:527-535.

Robin, C., and Heiniger, U. 2001. Chestnut blight in Europe: Diversity of Cryphonectria parasitica, hypovirulence and biocontrol. For. Snow Landsc. Res. 76:361-367.

Schabenberger, O., and Pierce, F. J. 2002. Contemporary Statistical Models for the Plant and Soil Sciences. CRC Press, Boca Raton, FL.

Schaupp, J. K., Jarosz, A. M., and Davelos, A. L. 1997. Intra-canker dynamics of Cryphonectria parasitica. (Abstr.) Phytopathology 87(suppl.):S85.

Schnurr, J. L., Ostfeld, R. S., and Canham, C. D. 2002. Direct and indirect effects of masting on rodent populations and tree seed survival. Oikos 96:402-410.

Silvertown, J., Franco, M., and Menges, E. 1996. Interpretation of elasticity matrices as an aid to the management of plant populations for conservation. Conserv. Biol. 10:591-597.

Springer, J. C., Davelos Baines, A. L., Fulbright, D. W., Chansler, M. T., and Jarosz, A. M. 2013. Hyperparasites influence population structure of the chestnut blight pathogen, Cryphonectria parasitica. Phytopathology 103:1280-1286.

Tattar, T. A., Berman, P. M., Gonzalez, E. Y., Mount, M. S., and Dollof, A. J. 1996. Biocontrol of chestnut blight fungus Cryphonectria parasitica. Arboric. J. 20:449-469.

Turchetti, T., Ferretti, F., and Maresi, G. 2008. Natural spread of Cryphonectria parasitica and persistence of hypovirulence in three Italian coppiced chestnut stands.For. Pathol. 38:227-243.

Van Alfen, N. K., Jaynes, R. A., Anagnostakis, S. L., and Day, P. R. 1975. Chestnut blight: Biological control by transmissible hypovirulence in Endothia parasitica. Science 189:890-891.

Viéitez, F. J., and Merkle, S. A. 2005. Castanea spp. chestnut. Pages 265-296 in: Biotechnology of Fruit and Nut Crops, Biotechnology in Agriculture Series, No. 29. R. E. Litz, ed. CABI Publishing, Cambridge, MA.

Xie, J., and Jiang, D. 2014. New insights into mycoviruses and exploration for the biological control of crop fungal diseases. Annu. Rev. Phytopathol. 52:45-68.

Yu, X., Li, B., Fu, Y., Jiang, D., Ghabrial, S. A., Li, G., Peng, Y., Xie, J., Cheng, J., Huang, J., and Yi, X. 2010. A geminivirus-related DNA mycovirus that confers hypovirulence to a plant pathogenic fungus. Proc. Natl. Acad. Sci. USA 107:8387-8392. 